\title{
Exploring Types of Graffiti at Jadara University in Jordan
}

\author{
Fadi Eissa Mousa Abu Eissa \\ School of Arts, Jadara University, Jordan \\ Luqman Rababah \\ School of Arts, Jadara University, Jordan
}

Correspondence: Luqman Rababah, School of Arts and Languages, Jadara University, Irbid, Jordan. P. O. BOX 733, Postal Code 20110, Jordan.

Received: September 1, 2020 Accepted: September 26, 2020 Published: September 28, 2020

doi:10.5296/jsel.v8i1.17749 URL: https://doi.org/10.5296/jsel.v8i1.17749

\begin{abstract}
This study aims to explore types of graffiti at Jadara University in Jordan. The study sample consists of (130) graffiti works from Jadara University, Jordan. The sample is randomly selected from the university public places. To achieve the purpose of the study, critical discourse analysis is used. The study revealed that the most common types of graffiti are: personal and emotional, social, national, religious, sport, and academic ones. In light of the results, the study recommends studying graffiti works from a psychological point of view to more understand the hidden messages in graffiti works found. Future research examining the differences in graffiti types and functions between different groups of students (e.g. in public vs. private university) is needed. Studying graffiti works from a psychological point of view to more understand the hidden messages in graffiti works found is also needed.
\end{abstract}

Keywords: Graffiti, Linguistic Landscape, Graffiti Types 


\section{Introduction}

Changes in life style have a significant impact on how people express themselves in different contexts. This had led to the emergence of new tools for communication as a result of these changes. Despite being used in past ages, graffiti signifies a major turning point in human communication since it has become a tool for sending hidden massages the speaker (in this case graffiti artist) uses to convey messages to others. Graffiti art works embody some cultural significance for that they portray an individualistic nature as the artist wishes to express his point of view about the world using open spaces. Furthermore, graffiti gives the chance that the art work is seen by as many people as possible while making sure that political, social, and economic issues are presented in the work.

Actually, people sometimes try to hide their identity while expressing their ideas. In this regard, graffiti has been used as a way to express one's private thoughts in public, and it has been defined as a linguistic phenomenon, as an expressive art form which involves simple written words or wall paintings that discuss serious topics that have a pragmatic hidden meaning (Wicks, 2012). Moreover, according to Longman Dictionary, the word graffiti is rooted in Italian "Graffiar" which means "to make marks on a surface". Furthermore, Reisner \& Wechsler (1974) pointed out that graffiti is considered as the plural form of the Italian word "graffito" which means a picture scratched on a surface. Accordingly, we all know that language is influenced by the society and the social context and affected by its culture as well (Labov, 1972).

Graffiti has value and importance in conveying certain messages as means of communication. It expresses individuals' sense of freedom or revolution they may feel or want to show. Additionally, it expresses social or political issues, or hopes and wishes for the future. In certain occasions, graffiti is just an attempt to make the surrounding environment more beautiful or tolerable. Thus, it can be concluded that graffiti's types are different from one place to another, based on the society's needs and concerns and is affected by many social variables, such as: age, gender, level of education, region... etc. Moreover, Banksy (2007:7) stated that there is "complex of motivation writings; the receptor of cultural belonging graffiti can generate for young people; the shifting threshold between art and vandalism". Such a dimension of discourse is the central study of Labov's sociolinguistics pragmatic theories.

This is important since it focuses on how Jordanian university students express their ideas through graffiti; the research reflects their interest and the issues they try to hide in public and difficulties they face in their life. Discussing such phenomenon helps the university society to understand university students more by analyzing their language and the psychology of the graffiti they are using to try solving the problems they face; since these difficulties are reflecting on their education. In fact, this study is beneficial for those who share political and religious interests, in addition to the fact that it could help those who are interested in cultural studies to explore the Jordanian social norms. Many studies have investigated graffiti in other cultures, but few were carried out in the Jordanian context (e.g. Al-Khawaldeh, Khawaldeh, Bani-Khair \& Al-Khawaldeh, 2017). Therefore, the proposed research tries to fill the gap in the Jordanian context regarding graffiti and contributes to several fields of linguistics. As it 
previously discussed, investigating such kind of discourse helps to shed light on university students and reveal their opinions and feelings toward a certain topic, which contributes to their educational process, and helps those who are interested in the field to learn more about this topic.

\section{Literature Review}

The researchers consulted a number of educational databases to look for studies addressing the communicative nature of graffiti art works. They were presented in chronological order. Loon (2014) analyzed the spatial behavior of graffiti artists using some graffiti paintings found in Amsterdam. The researcher selected some graffiti works found in Amsterdam which were analyzed using a checklist containing indicators of using spatial spaces in the different graffiti word. It was concluded that walls, squares and caravans are the most common places for graffiti works. Additionally, the use of graffiti is meant to send some massages (social, political... etc.).

El-Nashar and Nayef (2016) research analyzed vehicle graffiti found in different vehicles in Egypt. A sample of (614) written graffiti works were taken randomly from high-way and inner-city vehicles were analyzed using a checklist containing some linguistic features. The study found that there are different discourse domains contained in vehicle graffiti where they use religious expressions as one tool to send messages to the readers of them. It was also found that employing graffiti written texts talking about self or others was dominating these graffiti works.

Fraser (2016) examined the use of graffiti as one means for negotiating the different semantic construct at urban public places. Using some graffiti works $(n=28)$ found in Toronto and Los Angeles, the researcher analyzed some of the negotiated meanings convoyed by graffiti artists and found that urban public places are carefully designed to be a platform for graffiti works, and that graffiti artist uses them effectively to communicate some important messages for different audience.

Al-Khawaldeh, Khawaldeh, Bani-Khair and Al-Khawaldeh (2017) analyzed the content and communicative features of writings found on Jordanian universities' classrooms' walls, corridors, and washrooms and their relation to the socio-cultural values of the society in order to explore how universities help students voice their attitudes and thoughts. The study sample consisted of (378) graffiti written on universities walls.. The results of the study showed that graffiti serve different communicative language functions related to personal, social, national, religious, political, and taboo matters. The most salient linguistic features of these graffiti are simplicity and variation.

\section{Data Collection and Methodology}

The study adopted the qualitative design where Critical Discourse Analysis (CDA) and graffiti works were analyzed. The population of the study included all the graffiti art works 


\section{Al Macrothink}

Journal for the Study of English Linguistics

ISSN 2329-7034

2020, Vol. 8, No. 1

found in the buses, toilets, classrooms and walls at Jadara University. The sample of the study consisted of (130) graffiti art works form Jadara university which were selected from the university public places to represent different aspects and perspective of language. There are several issues that have been tackled in this study, thus unlike the quantitative approach, the qualitative one is more subjective since the researcher collected his data from natural settings, transliterated it, translated it then analyzed it based on the semantics and sociolinguistics theory.

The researcher has adopted Critical Discourse Analysis (CDA) focusing on analyzing graffiti found in the different locations at Jadara University. These were collected from walls, toilets, doorways, and other locations. In analyzing the graffiti writings, the collected sample was first read carefully for several times to develop general themes about their content. Then, these themes were grouped into separate categories according to their content and contextual meaning.

\section{Discussion and Findings}

In order to achieve the aim of the study, the researcher used Critical Discourse Analysis where following findings obtained. The types of graffiti at Jadara University are personal and emotional, social and national, sport, academic and religious.

\subsection{Personal and Emotional Themes}

As known, graffiti, as an art, was presented as a tool for expressing one's emotions and feelings at the personal level. The graffiti collected in this study implied that students at Jadara University use graffiti to convey some personal messages mirroring their inner feelings. For example, a one graffiti work was as follows:

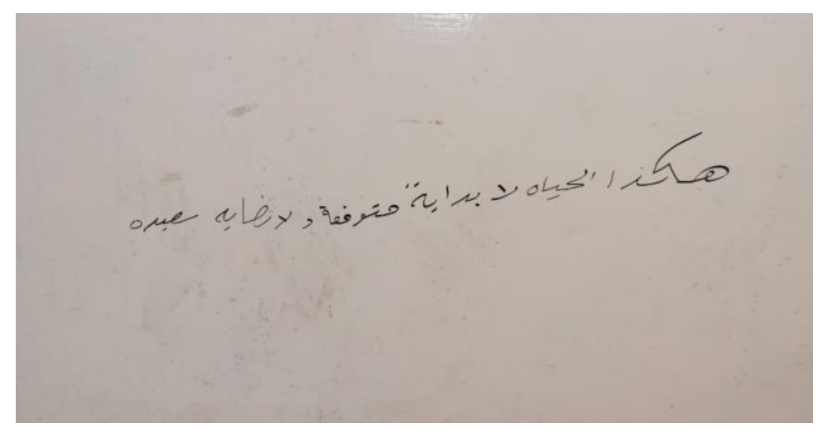

As seen in this graffiti work, the student used simple language to indicate his feeling of frustration and loss of hope in this word. It means that this student is expressing his/her resentment toward life he/she is living now. Such feeling might be attributed to several personal or social factors making life something repulsive for the student. His/her use of such a language (e.g. و ولانهاية سعيدة - wala: niha:ja saGi:da "There is no happy ending") represents a form of melancholia. This maybe a wrong message to send to other students as it sends wrong messages to others that life worths nothing despite the fact that students in the university ought to have a much brighter look to life. 
In another example, a student is expressing his love to a girl her name begins with ' $F$ '.

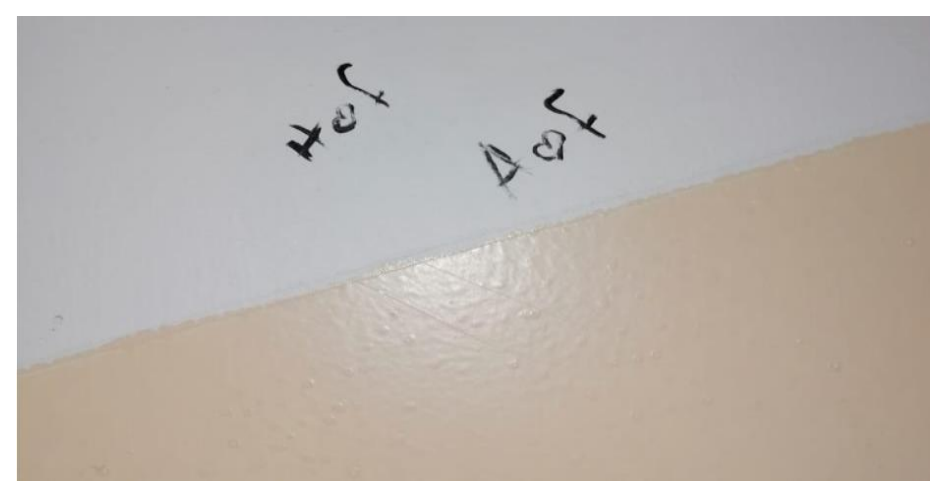

This example has several human meanings. One is that the male or female student cannot express his/her feelings to a colleague (male or female). This graffiti may also be a form of emotion ventilation used by the student to send a certain message to the other; a form of stating his / her love to a colleague. Such graffiti may also be an indicator of emotion supersession in an oriental society giving no chance for expressing love openly. Also, this may imply that there is a form of social or economic variation between the sender of the message and its recipient. The use of English initials is a type of expressing love, either by the male or the female to let him / her know that someone has feelings and cannot express them before other people.

Graffiti at the personal level as indicated by Al-Khawaldeh, Khawaldeh, Bani-Khair and Al-Khawaldeh (2017) is a communicative tool reflecting what the person is feeling about different things in his life. Some may express their past experiences with others and make judgments about life as a whole. In the following example, this graffiti mirrors that the student wrote this graffiti to show that he has been exposed to different negative experiences with various people and this has changed his perspective to life.

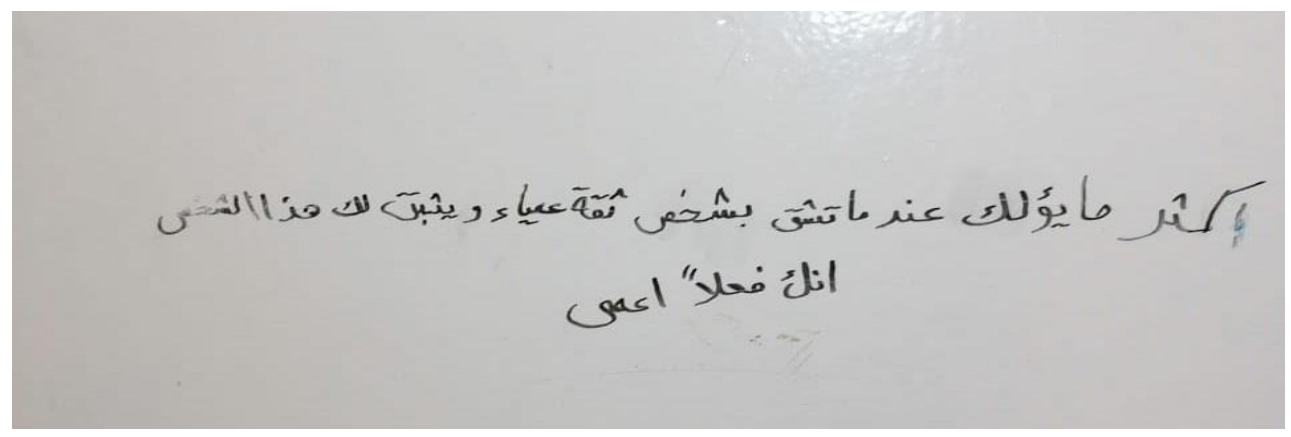

This graffiti uses strong words such as (يؤلمك - joflimvka - "hurts you") which signifies that this person was deeply hurt by another one, whether at the personal or the transactional levels. For example, as a student shares his secrets with friends, the one being addressed by such graffiti may have disclosed secrets about the writer of the graffiti, which has affected him at the personal level. Another explanation for such graffiti is that a student (male - 


\section{Mll Macrothink}

female) was in a romantic relationship and was cheated on by his / her beloved.

The following example illustrates that there are positive messages in the graffiti work. This image shows that there are some illuminating examples about the value of some relations between persons; to the degree that they use it as graffiti work to be written on walls and never been overlooked or forgotten.

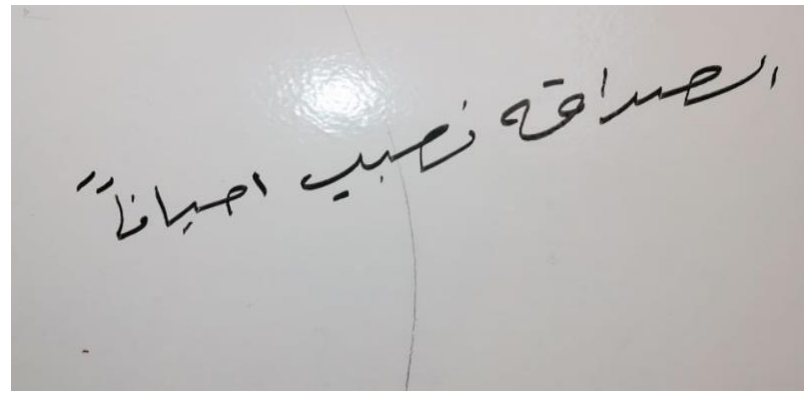

For a reader who is having great friendships with others, this graffiti intensifies his feelings about the value of friendship as something invaluable in one's life. The student used the word (الصداقة - as-sada:qa - "friendship") which has positive meanings for both the writer and the reader. He/she is trying to install the importance of friendship in the heart and soul of the reader by emphasizing the importance of such relationship between people. Another explanation of such graffiti maybe taken from a negative perception; as the writer has experienced negative friendship with a person / persons that made him believe that even friendship maybe illusive. Despite the fact that the writer has been in a close relationship with his / her friend, such a friend hasn't been honest or sincere in his emotions as being insincere in showing his friendship too.

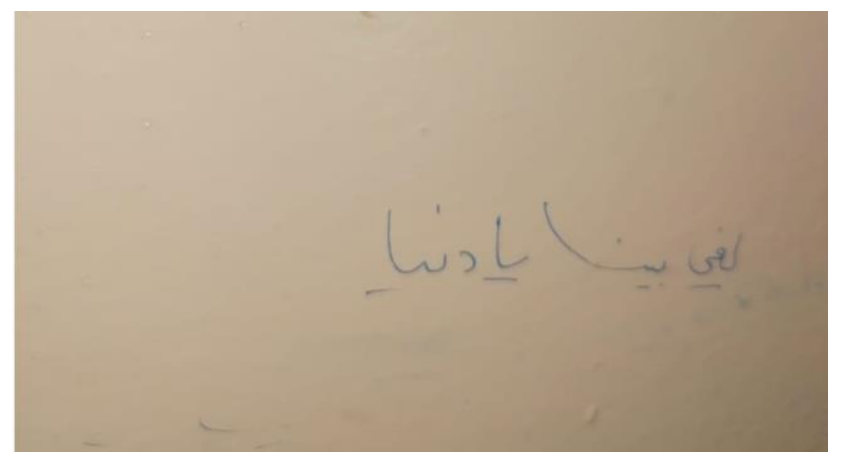

This example of personal graffiti themes shows a kind of uncertainty in this life. The writer of the graffiti shows doubtful thoughts about what life holds for him/her. Such a message is inaccurate in many cases and reflects low levels of religiousness as the writer does not believe in fate, and that Allah is the responsible of everything happening to a person.

\subsection{Social and National Themes}

Social and national themes are one of the most prevalent topics addressed in graffiti works. 


\section{Ml Macrothink}

These themes mirror a sense of belonging and a reflection of the most common social values dominating the society. The examples being presented in this theme are collected from places at Jadara University, meaning that they do not necessary provide a complete picture about the social and national norms and traditions in the Jordanian society. The following example illustrates the connection between the writer and one of the most significant national symbols among Arab and Muslims which is Al-Quds - Jerusalem.

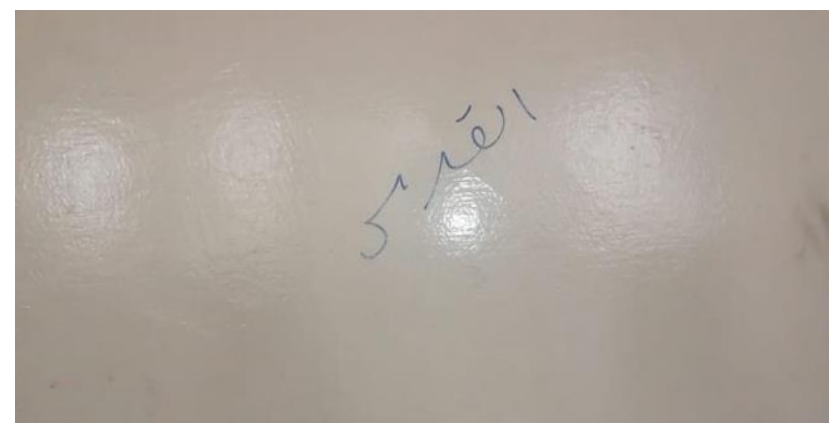

In this example, the writer shows his/her national origins as he/she maybe a Palestinian refugee; wanting to say that Al-Quds - Jerusalem will not be forgotten despite the Israeli occupation for this sacred city for more than fifty years. Also, such graffiti is a reminder of some national values, which are to protect the soil of your own country and to be a martyr in defending this city. For Jordan national values, Al-Quds - Jerusalem was and still an occupied city needs to be freed from the hands of the Israelis who want to change it drastically as they believe it is the place of Solomon template; the one they believe that it represents the resurrection of the Jews on earth . Additionally, and despite that Jerusalem is in the hand of Jews for more than fifty years, the political leadership in Jordan has the custody on the holy places in this city that reflects a main concern for this leadership. It is convoyed in the media messages. The next example is an evidence of the national and social values of some students using graffiti as a form of communicating messages. Using the name of one of the most well-known Jordanian poets ( عرار - Gara:r) shows such national values

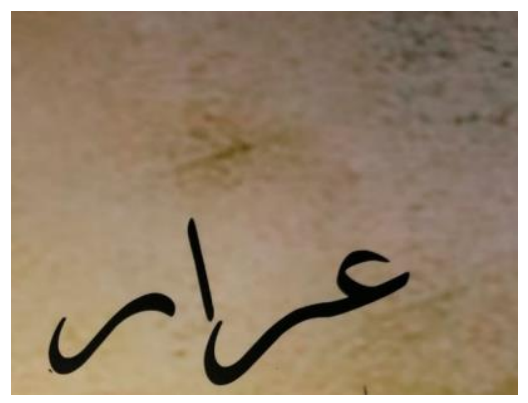

Mustafa Wahbi Tal (Arar) is one of the most known Jordanian poets. He represented the Jordanian values such as hospitality, courage and sense of humor. The name of this poet as being used in graffiti sends important messages to all readers. These include that there is a need to return to our national values as a way to promote our style of life in these days. Arar was always calling for independence from the foreigner as he believed that the foreigners are 


\section{Macrothink}

the colonists and they want to steal the wealth of their colonies. The writer of this graffiti reminds the reader that there are great men in the history of Jordan who were well-informed about the plans of outside powers and their desires to occupy Jordan and making all their efforts that this great country never develops by exploiting its national resources so as a comprehensive social and economic progress maybe achieved.

Furthermore, the writer of this graffiti may be from another nation who admires the works of Arar as a pioneering poet since the independence of Jordan in 1946. When Arar wrote poetry, he represented the feelings and emotions of poor people as he addressed main concerns of those underprivileged and for those who live on the margin. For this reason, the writer of this graffiti has deep admiration of this great poet. Some of the graffiti works found at Jadara University show deep social values among Jordanians. As seen in the following example, the writer uses (جيرة الله على منسف - dzi:rtalla Sala mansaf - I invite you to eat Mansaf) which is one of the most common social values among Jordanian; being generous and great hosts as Mansaf is one of the most well-known traditional meals.

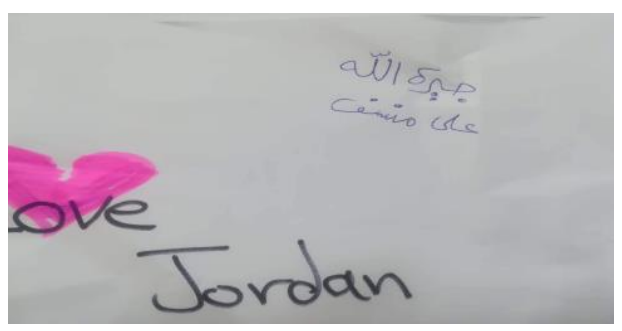

Inviting others to eat Mansaf is a sign of being both a great host and that those being invited deserve the hospitality as being respected and to show great manners; thus, worth making them Mansaf. Mansaf now is expensive meal as it needs meat, yogurt, rice, and Jamid (جميد). This means that inviting a person to eat Mansaf will be an economic burden for the host. Nonetheless, he is willing to have such a burden in order to invite other people to have lunch or dinner at his house; presenting a true example of generosity to the world. The following graffiti illustrates how much Jordanians are proud of their kin and clans. It is well-known that Arabs are always proud of their origins and clans and have always used poetry and other forms of media to make others been acquainted of their origins.

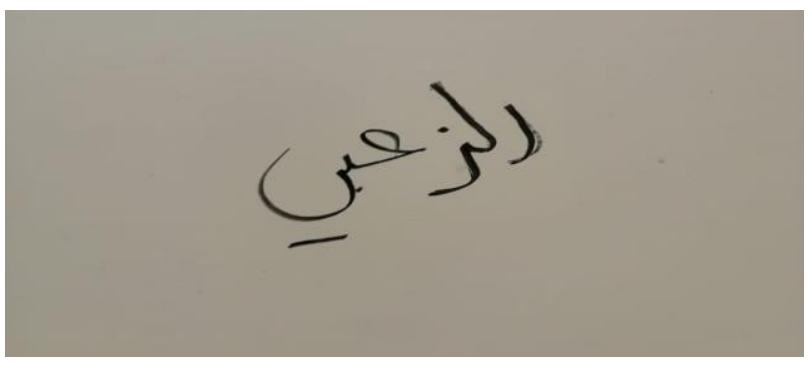




\section{Macrothink}

The writer of this graffiti is from Al-Zou'bi clan, one of the biggest clans in Jordan, Syria and Palestine. Youth in general show special interest in where they come from; wish to tell others that they come from a big family that backs them when there is a problem. They are sending message that they can protect themselves against other students in the case of any disagreement; and ready to defend their rights. Some of the graffiti works extend to express nationalism at the country level which is the most prevalent and common use of graffiti in illustrating one's love for his country. Such graffiti sends different messages for the reader such as patriot feelings of Jordan as a country for all Jordanians.

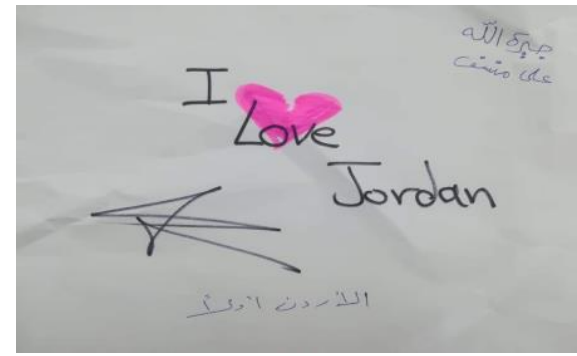

As seen in the previous graffiti, the writers use a form of romantic graffiti (using Cupid Heart) to indicate true love between those writing this graffiti and their home country, which is in this case Jordan. This may show a sense of patriotism and belonging to Jordan, the desire to defend it against enemies with hearts and souls of all Jordanians.

\subsection{Religious Theme}

Jordan is a Muslim Arab country where religiosity is high among Jordanians, although youth are the least spiritual among them. However, the use of religious graffiti is heavily found in the graffiti works at Jadara University. Among these, there are calls for mentioning Allah and his Prophet Mohamed. Such calls are very common in different places in Jordan such as streets and buildings which mean that Jordanians show high levels of religiosity. The following graffiti shows two religious sentences, or calls to mention Allah and his Prophet, to be specific.

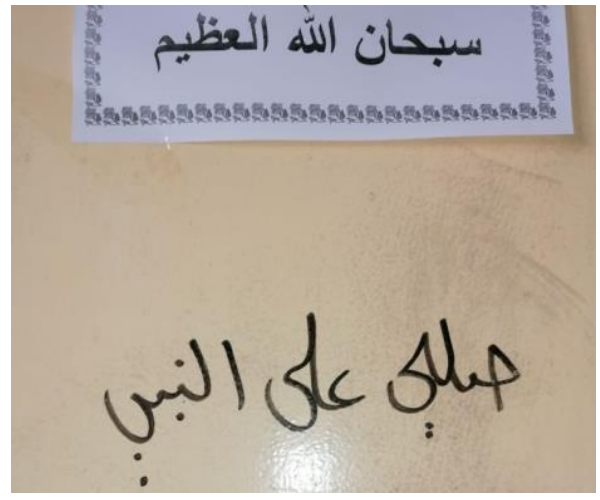




\section{MInstitute ${ }_{\text {Mnk }}^{\text {Macrothink }}$}

The first sentence or pray (سبحان الله العظيم - sobha:n allah al-Yadi:m - "Glory be to Allah the Greatest") which is a sincere call for all who read this graffiti to mention Allah as the Almighty, who has in his hands the strings of everything happening to man on this earth. Also, if a Muslim mentions Allah, he will have His blessings and this leads to comfort when one is feeling anxious and depressed. Additionally, in Islam, calling others to do the right thing such as mentioning Allah means that the caller of such action will have the righteous deeds and this makes him a better Muslim.

In the same graffiti, there is another call (صلي على النبي - Sally a'la Alnaby - Pray on the Messenger), urging readers to mention Prophet Mohammed to obtain righteous deeds as this is a simple action "Just mentioning Prophet Mohammed by saying: (اللهم صلِ على سيدنا محمد Clla:hom sali: Gala sajidena mohmad - "Allah blessings and peace upon our Prophet Muhammad") which is a response to a call given by Allah to all Muslims when saying:

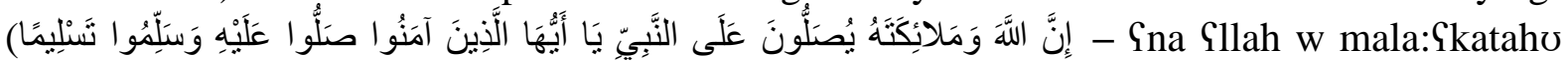

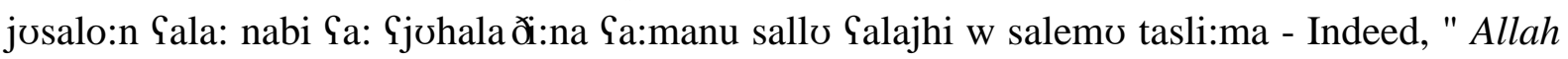
confers blessing upon the Prophet, and His angels [ask Him to do so]. O you who have believed, ask [Allah to confer] blessing upon him and ask [Allah to grant him] peace") [Al-Ahzab: 56]. Such call by Allah means that all who mention His Prophet Mohammed will obtain blessings and will enter heaven in the afterlife. The next graffiti is one form of praying used by Muslims to thank Allah for his blessings. This prayer expresses being satisfied with what Allah gives to His servants, who are this case are Muslims.

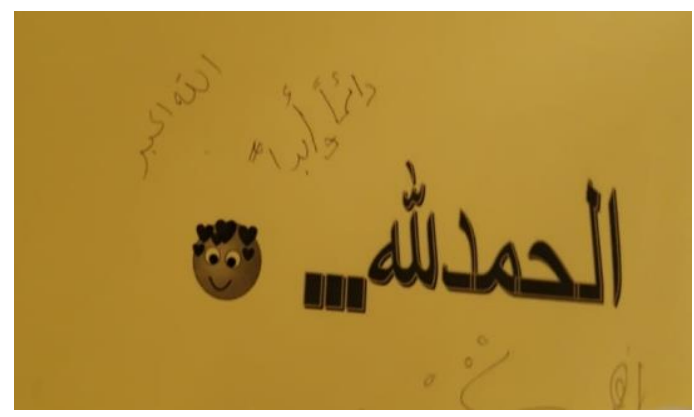

The expression (الحمدلله - Calhamdvlila:h - "Praises be to Allah") is a call by the Almighty for all Muslims to be content with what He offers to them. Such an expression shows the ultimate level of satisfaction of the status quo one is living. The following graffiti presents indications about one of the most important worships in Islam, Praying. As known, this worship is imposed on Muslims five times a day. Students may use the worship place (المصلى - Almusala - Oratory) at least two times while being in the university. Using graffiti for leading students to go to the oratory signifies that the writer is very careful in letting his colleagues be well-informed about the location of this place.

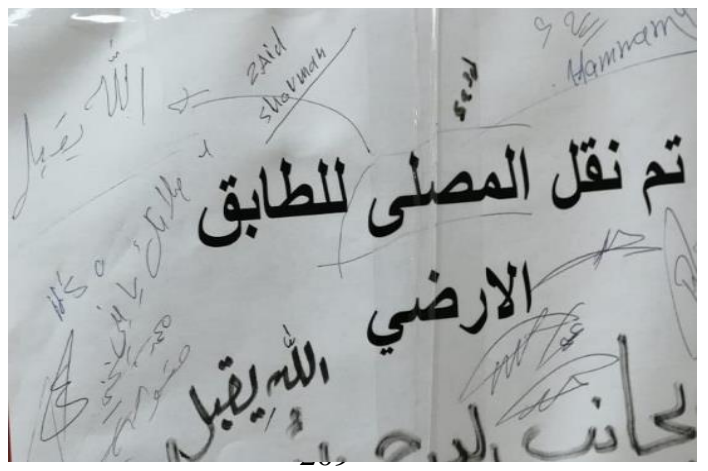




\section{Mll Macrothink}

sala:tok ja: bonai - "your pray my child") which may be written by someone old like an administrator or a faculty member to remind students that praying is a pillar in Islam as any other worship (The five pillars of Islam, شهادة أن لا إله إلا الله - Jaha:dat Gan la: Gila:h Gilla Gallah - "There is no God but Allah"). Praying does not fall from the shoulders of the Muslim at any case and at any time, but the other pillars of Islam may fall from the shoulders of a Muslim. For example, a sick Muslim may not fast, and the poor do not pay Zakat, but every Muslim must pray to Allah at certain times.

In the same graffiti, a pray (الله يقبل - Allah yekbel - Callah jiqbal - "May Allah accept your prayer") is said when a Muslim ends his praying. This sentence is like a plea to Allah to accept one's praying and is said between Muslims as a form of calling Allah that He accepts this worship.

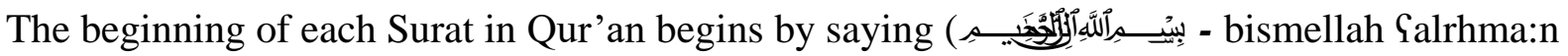
Galrahi:m - "In the name of Allah, The All-Merciful, the Ever-Merciful") which applies to any action a Muslim embarks in doing, it must begin with the name of Allah to make it blessed by Him. It signifies that Allah is merciful with His servants and $\mathrm{He}$ is capable of forgiving any sin a Muslim commits.

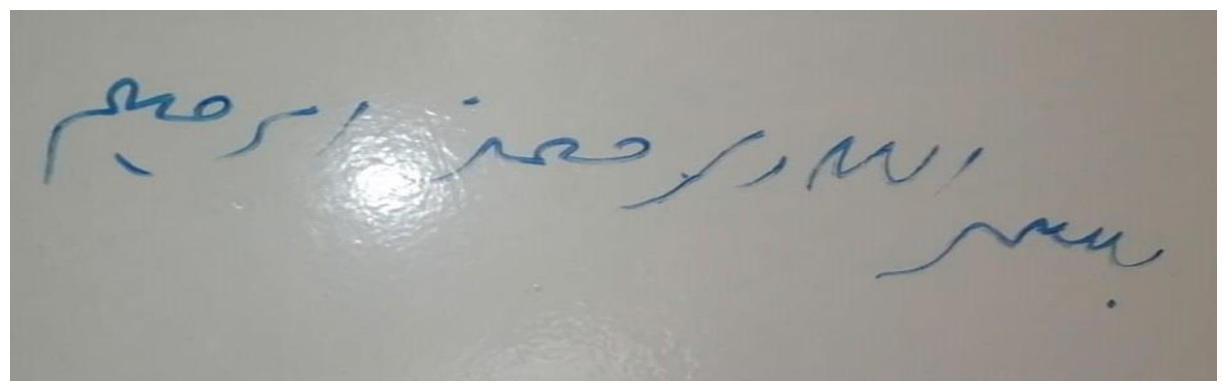

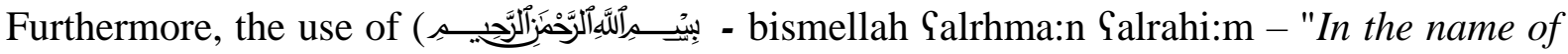
Allah, The All-Merciful, the Ever-Merciful") is a wake-up call for those forgetting that Allah is there around them, watching what they are doing. Another example of using graffiti for religious purposes is writing: (الحمدله عند الحزن وعند الفرح) - Salhamdolillah Sinda Salhozni w Sinda Salfarahi - "Thanks Allah in good and in Sorrow"). Such a pray is said as indicator of Muslims acceptance what happens to him at all times. Such a sentence embodies believing in fate, that all is coming from Allah and people are not important enough to affect any course of action in life.

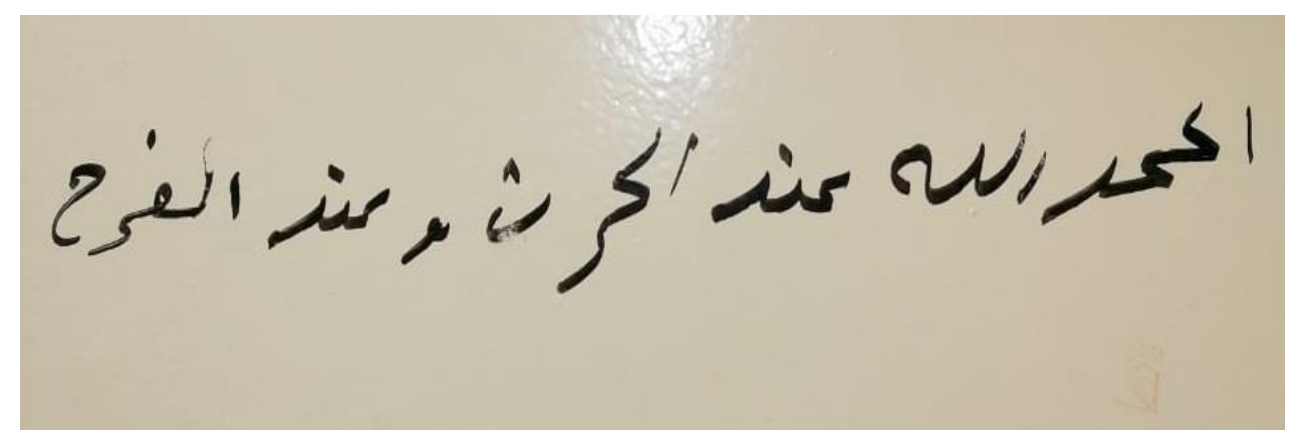




\section{$\triangle$ Macrothink}

\subsection{Sport Theme}

2020, Vol. 8, No. 1

Sport is a major theme in the life of university students as the majority of them are fans of certain clubs or international teams. For this reason, it is logical to find that sport as a theme is common in graffiti works. The following graffiti has the name of one of the major soccer teams in the world that is Real Madrid. The writer of this graffiti is by no doubt is a fan of this football club. He wishes to promote his team to others in the university by writing its name on the walls. It may be also a message for those supporting other teams in the Liga. The rivalry between Real Madrid and Barcelona is one of the main topics among youth in Jordan, especially university students.

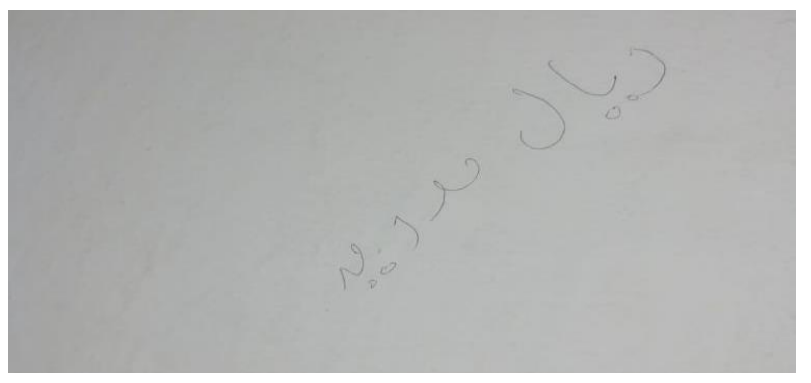

Another graffiti shows the slogan of one of the most famous English premier league clubs, Liverpool. This slogan is always repeated by this club fans who love their football team to great extent and they often shout it in the Anfield, the stadium of Liverpool. They are expressing their love and support for this football team, and supporters out of England use graffiti to express such emotions and feelings; which is the case in this example. The fans of Liverpool are all around the world as this football team is one of the most famous teams worldwide. In addition, Mohammed Salah, known as Mo Salah who is one of the most Arab greatest players plays with this team has contributed in the success of this team by leading them to win champions league in 2019 season.

\subsection{Academic Theme}

Academic themes are supposed to occupy a significant place in the life of students, so, it is logical to find that the many graffiti works at Jadara University are dedicated to academic purposes. Nonetheless, the majority of the graffiti works found by the researcher were limited to personal and religious themes, which makes it surprising as the university which is an academic place that is supposed to contain various academic themes graffiti works. As seen in the following graffiti work, this art is used for negative purposes, which is academic 


\section{Macrothink}

cheating. The writer thinks that the exam will contain a question that can be answered using what is written on the wall of the class. He used graffiti as a tool of gaining higher grades in the exam, which contradicts with the basic assumptions in graffiti. This art was established as a means for expressing specific messages (social, political, personal...) that cannot be said openly by the artist. This means that students are using graffiti in away opposing what is assumed when employing graffiti works.

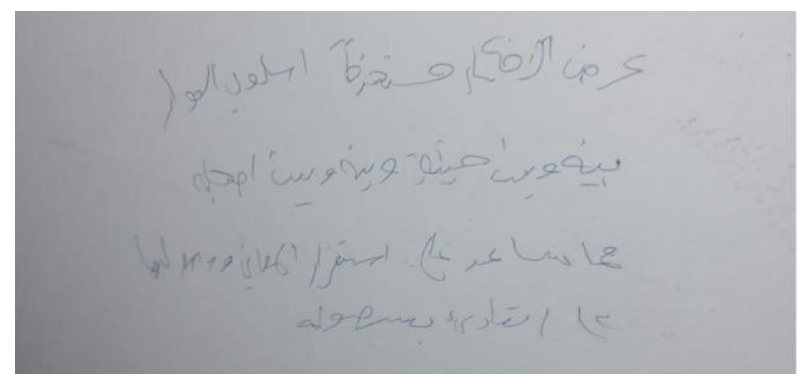

Another example of the academic themes found in graffiti works is using some phrases to wish students good luck when entering a certain exam. This exam maybe very difficult for students as who writes this graffiti works believes that he and the other students need praying to be able to pass it. He/she wrote such a pray in addition to some Chinese letters. This may indicate that this course is very difficult for students and one of them is expressing that by using Chinese letters. Furthermore, it might be a message for the course instructor to make the exam easy for the students as they experience hardships and agony in trying to pass it; a difficult thing to do for most students.

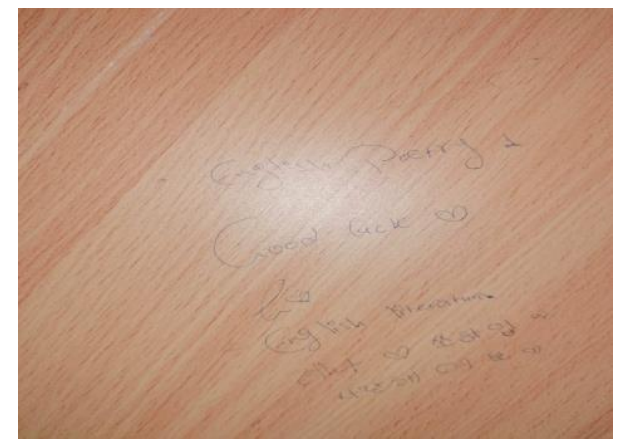

\section{Conclusion and Recommendations}

The purposes of the present study were to explore the types and functions of graffiti works at Jadara University in Jordan. The study aimed to examine the different types of graffiti made by students at Jadara University. To do this, the researcher collected (130) graffiti works which were analyzed by using CDA.

By exploring the types of graffiti at Jadara University in Jordan, the researcher found that personal themes were the most prevalent graffiti works used which might be logical as university students are at a critical age since they are adolescents who are searching for their identity. Therefore, personal themes were the most prevalent in graffiti works since they 
represent ventilation for those students. Moreover, the results of this study carry various theoretical and practical implications for those engaged in researching this field. For the theoretical implications, it is considered that the most important outcome is that the finding of this study highlights the need for future research and provides the foundation material for future researchers to use as the basis for their own studies.

One of the limitations is that the themes covered in the selected graffiti art works do not represent a wide array of themes and they are traditional in the topics being addressed in graffiti works. This means that there is a need for examining different academic locations such as public universities to obtain a much wider sample of graffiti works. However, future studies should take into consideration the variation of graffiti themes as graffiti being a form of modern art should represent the political, social and religious values among students in different universities and they should be a part of their academic life. Future research examining the differences in graffiti types and functions between different groups of students (e.g. public vs. private universities) is needed. Moreover, studying graffiti works from a psychological point of view to understand more the hidden messages in graffiti works is also needed.

\section{References}

Al-Khawaldeh, N. Khawaldeh, I., Bani-Khair, B. \& Al-Khawaldeh, A. (2017). An exploration of graffiti on university's walls: a corpus-based discourse analysis study. Indonesian Journal of Applied Linguistics, 7(1), 29-42.

Almwajeh, M., \& Rababah, L. (2018). Literature is the best tool of awaking moral understanding and evaluation: Wendell Berry's The Long-Legged House. AWEJ for Translation \& Literary Studies, 2(2), 69-80.

Almwajeh, M., \& Rababah, L. (2019). There is more to it than meets the eye: an intercultural study of religious speech acts between Jordanian and American students. International Journal of Linguistics, 11(1), 34-45.

Alshehab, M \& Rababah, L (2020). Lexical Legal Problems committed by translation students When translating English legal sentences into Arabic at Jadara University in Jordan. The Asian EFL Journal, 24(3), 120-134.

Banikalef, A. A., \& Rababah, L. (2018). Gender differences and emotional expressiveness on Facebook: An analysis of prosodic features among Jordanian Facebookers. Studies in Linguistics and Literature, 2(3), 180-184.

Banksy, A. (2007). Wall and piece. Mainaschaff: Publikat.

Cox, S., Kirkham, S., Love, E., \& Mayouf, M. (2017). Using a socio-technical approach to explore perceptions of the graffiti culture. Proceedings of the 3rd International Workshop on Socio-Technical Perspective in IS development (STPIS'17), 75-82.

Dombrowski, Q. (2011). Walls that talk: Thematic variation in University library graffiti. 
Journal of the Chicago Colloquium on Digital Humanities and Computer Science, 1(3), 1-13.

El-Nashar, M., \& Nayef, H. (2016). 'Discourse on the Go': Thematic analysis of vehicle graffiti on the roads of Egypt. Advances in Language and Literary Studies, 7(5), 227-239.

Fraser, A. (2016). Urban prophets: Creating Graffiti as a means of negotiating the constructs of urban public spaces. Stream: Culture / Politics / Technology, 7(2), 32-42.

Hughes, M. (2009). Street art \& Graffiti art: Developing an understanding. Unpublished Master Thesis, Georgia State University, USA.

Jdaitawi, M., Ishak. N., Taamneh, M., Gharaibeh, M., \& Rababah, L. (2011). The Effectiveness of Emotional Intelligence Training Program on Social and Academic Adjustment among First Year University Students. International Journal of Business and Social Science, 2(24). 251-258.

Karlander, D. (2016). Fleeting graffiti: Backjumps, mobilities and metro semiotics. Tilburg Papers in culture studies, 161, 1-18.

Labov, W. (1972). Some principles of linguistic methodology. Language in Society, 1(1), 97.

Loon, J. (2014). "Just writing your name?" An analysis of the spatial behaviour of graffiti writers in Amsterdam. Belgeo, 3, 1-19.

Norvaisaite, V. (2014). Environmental communication in street art: Motivations \& messages of reverse graffiti greators. Unpublished Master Thesis, Erasmus University Rotterdam, Netherlands.

Reisner, R., \& Wechsler, L. (1974). Encyclopedia of graffiti. New York: Galahad Books.

Rababah, L. (2020). Speech act analysis of WhatsApp statuses used By Jordanians. Review of European Studies, 12 (2), 28-32.

Rababah, I., Rababah, L. (2017). Investigating Arabic to Speakers of Other Languages (ASOL) Lecturers' Attitudes towards Utilizing Flipped Classroom Instruction (FCI): A Qualitative Study at Jordanian Public Universities. International Educational studies, 10(7), 80-91

Wicks, B. (2012). ROA's graffiti at 209 Mitchell Street, Atlanta, Georgia. Southern Spaces.10 (2), 24-35.

Vanderveen, G., \& Eijk, G. (2016). Criminal but beautiful: A study on graffiti and the role of value judgments and context in perceiving disorder. European Journal on Criminal Policy and Research, 22, 107-125. 


\section{Copyright Disclaimer}

Copyright for this article is retained by the author(s), with first publication rights granted to the journal.

This is an open-access article distributed under the terms and conditions of the Creative Commons Attribution license (http://creativecommons.org/licenses/by/3.0/). 